\title{
Correction
}

\section{Correction to: A binding-block ion selective mechanism revealed by a $\mathrm{Na} / \mathrm{K}$ selective channel}

\author{
Jie $\mathrm{Yu}^{1}$, Bing Zhang ${ }^{2,4,5}$, Yixiao Zhang ${ }^{1}$, Cong-qiao $\mathrm{Xu}^{3}$, Wei Zhuo ${ }^{1}$, Jingpeng $\mathrm{Ge}^{1}$, Jun $\mathrm{Li}^{3}$, Ning Gao ${ }^{1 凶}$, \\ Yang $\mathrm{Li}^{2 \bowtie}$, Maojun Yang ${ }^{1 凶}$ \\ ${ }^{1}$ Ministry of Education Key Laboratory of Protein Science, School of Life Sciences, Tsinghua-Peking Joint Center for Life \\ Sciences, Beijing Advanced Innovation Center for Structural Biology, Tsinghua University, Beijing 100084, China \\ ${ }^{2}$ Key Laboratory of Receptor Research, Shanghai Institute of Materia Medica, Chinese Academy of Sciences, Shanghai \\ 201203, China \\ ${ }^{3}$ Department of Chemistry and Key Laboratory of Organic Optoelectronics and Molecular Engineering of the Ministry of \\ Education, Tsinghua University, Beijing 100084, China \\ ${ }^{4}$ University of Chinese Academy of Sciences, Beijing 100049, China \\ ${ }^{5}$ Anesthesiology, Shanghai First Maternity and Infant Hospital, Tongji University school of Medicine, Shanghai 201203, China \\ $\bowtie$ Correspondence: gaon@pku.edu.cn (N. Gao), Liyang@simm.ac.cn (Y. Li), maojunyang@tsinghua.edu.cn (M. Yang)
}

CORRECTION TO: PROTEIN CELL 2018, 9(7):629-639

HTTPS://DOI.ORG/10.1007/S13238-017-0465-8

In the original publication the PDB numbers were not cited. The correct version is provided in this correction article.

Three-Dimensional ctyo-EM density maps and coordinates of Ynal has been deposited in the Electron Microscopy Data Bank under the accession number EMD-6805 and deposited in the RCSB Protein Data Bank under the accession code $5 \mathrm{Y} 4 \mathrm{O}$.

\section{OPEN ACCESS}

This article is distributed under the terms of the Creative Commons Attribution 4.0 International License (http://creativecommons.org/ licenses/by/4.0/), which permits unrestricted use, distribution, and reproduction in any medium, provided you give appropriate credit to the original author(s) and the source, provide a link to the Creative Commons license, and indicate if changes were made. 